\title{
Interactive comment on "Reduced growth with increased quotas of particulate organic and inorganic carbon in the coccolithophore Emiliania huxleyi under future ocean climate change conditions" by Yong Zhang et al.
}

Anonymous Referee \#2

Received and published: 5 September 2020

This study examined the interactive effects of multiple environmental drivers, including $\mathrm{CO} 2$, temperature, light, dissolved inorganic nitrogen and phosphate, on the physiology of the ecologically important coccolithophore Emiliania huxleyi. The authors used a novel step-wise laboratory manipulation method, in order to compare the single driver effects with the cumulative effects of multiple drivers. The results suggest that the simultaneous manipulation of ocean edification, warming and decreased nutrient ( $\mathrm{N}$ and $\mathrm{P})$ concentration significantly decreased the growth rate and increased the cellular carbon quotas. These findings will contribute to our understanding of the coccolithophore- 
related ecological and biogeochemical responses to future ocean global change.

Overall, the experiment was well designed and the data was carefully analyzed. The manuscript is also well structured and written. However, I have some major comments listed below.

1. The authors refer the manipulated conditions as "future conditions" in the discussion. Therefore, it would be better to justify why these environmental conditions represent the future global change scenario. For example, the irradiance levels and the nutrient concentrations set up for the experiment are not within the ranges listed in Table S1. The physiological response of $\mathrm{E}$. huxleyi would be different under different levels of environmental conditions (i.e. irradiance and nutrient). How will the results of this study be extrapolated to the future global change scenario?

2. The coccolithophore Emiliania huxleyi is a cosmopolitan species. Previous studies have shown strain-specific responses of E. huxleyi to environmental changes (especially ocean acidification). I would suggest the authors to expand the discussion on Table 5 a little further.

Some other specific comments:

Lines 163: "low nitrogen was added..." I don't think this is a correct expression of introducing low nitrate concentration. Could the authors also specify how the nitrate concentration was reduced? The same for line 164, "low phosphate was added...".

Line 269: The cell diameter was measured for the whole coccosphere, with coccoliths attached. However, both PIC quota and PIC/POC ratio was changed by different experimental manipulations, especially by alteration of $\mathrm{pCO} 2$. This would have also resulted in changes in coccolith thickness. I was wondering if the authors have considered this when calculating the cell-volume normalized particulate organic elemental quotas.

Lines 527-531: This sentence is too long, please split to two.

Line 556: "low-pH inhibited growth.." Here the authors indicate it was mainly the effects

Printer-friendly version

Discussion paper 
of $\mathrm{pH}$ instead of changing $\mathrm{pCO} 2$, please add some explanations on this.

Line 559: Please add a reference after the sentence "photosynthesis under the high light regime could generate more energy-conserving compounds".

Line 561: Please specify the strain of the E. huxleyi examined in Jin et al., as well as in line 569.

Line 575: Why was PIC quota increased under high light? Please add some explanations.

Line 617: The sentence "released organic compounds should be negligible..." contradicts to the previous expression of "over-synthesis of cellular organic carbon might be released as dissolved organic carbon.." in lines 612-613.

Fig. 1 Please label the symbols in the graph for a better understanding of the treatments.

Fig. S1 I think it would be better to move this figure to the main manuscript, instead of being in the supplementary materials, in order to make a better understanding of the step-wise experimental design.

Fig. S11 How was the RNA concentration measured? This is not presented in the methods section.

Interactive comment on Biogeosciences Discuss., https://doi.org/10.5194/bg-2020-213, 2020. 